\title{
Penentuan Peminatan Pada Kurikulum KKNI Untuk Setiap Program Studi di Universitas Madura Secara Sistemik
}

\author{
Mohammad $^{1}$, Abd. Wahab Syahroni ${ }^{2}$ \\ ${ }^{1}$ Ilmu Hukum, Universitas Madura Jl. Raya Panglegur Km 3,5 Pamekasan, Madura \\ ${ }^{2}$ Teknik Informatika, Universitas Madura Jl. Raya Panglegur Km 3,5 Pamekasan, Madura
}

\section{KEYWORDS}

KKNI, peminatan, sistem pendukung

keputusan, mahasiswa, profile matching.

\section{CORRESPONDENCE}

Phone: +6282330511716

E-mail: roney@unira.ac.id

\section{A B $\mathbf{S}$ T $\mathbf{R}$ A $\mathbf{C}$ T}

Pada tahun akademik 2016/2017 semester gasal, Universitas Madura telah menerapkan kurikulum KKNI, salah satu hal pokok yang ada pada kurikulum KKNI adalah peminatan matakuliah mahasiswa. Setiap program studi memiliki aturan peminatan yang berbeda. Namun pada umumnya, Salah satu syarat mahasiswa dapat memilih peminatan jika sudah menempuh beberapa SKS tergantung pada aturan masing masing program studi. Selama ini, mahasiswa meminta saran kepada dosen wali untuk memilih peminatan yang cocok untuk dipilih. Ada pula yang memilih peminatan berdasarkan banyaknya peminatan yang di pilih oleh teman mahasiswa lainnya (ikut ikutan).

Tujuan utama penelitian ini adalah untuk merancang dan membangun sebuah sistem pendukung keputusan yang dapat membantu dosen wali dan mahasiswa pada masing masing program studi yang ada di universitas dalam memberikan rekomendasi peminatan yang tepat untuk setiap mahasiswa dengan menggunakan metode profile matching. Langkah pertama yang dilakukan untuk mengimplementasikan metode ini adalah dengan menentukan matakuliah pendukung peminatan pada masing masing program studi sebagai kriteria, menentukan core factor dan secondary factor matakuliah pendukung peminatan yang ditentukan oleh ketua program studi, mengambil nilai semua matakuliah yang pernah di tempuh mahasiswa dari SIMAT(Sistem Informasi Manajemen Akademik Terpadu) Universitas Madura, menentukan nilai profile pada setiap peminatan, menentukan nilai GAP, konversi nilai GAP ke dalam bobot nilai, menghitung nilai core factor dan secondary factor, memilih nilai tertinggi pada masing masing peminatan, kemudian sistem memberikan rekomendasi peminatan kepada mahasiswa.

Dari hasil ujicoba menggunakan metode black box dapat disimpulkan bahwa semua fungsionalitas sistem sudah dapat berjalan dengan baik. Sedangkan hasil survei menggunakan skala likert terhadap 30 responden dalam hal ini adalah mahasiswa menyatakan aplikasi ini layak untuk digunakan pada setiap program studi di universitas madura berdasarkan indeks kepuasan menggunakan skala likert dengan nilai $82,67 \%$ yang berarti responden sangat setuju..

\section{PENDAHULUAN}

Universitas Madura merupakan Universitas Swasta yang ada di pamekasan, Universitas Madura memiliki 6 Fakultas dengan 10 Program Studi antara lain Fakultas Hukum memiliki 1 program studi yaitu ilmu hukum, Fakultas Keguruan dan Ilmu Pendidikan memiliki 3 program studi yaitu pendidikan bahasa dan sastra indonesia, pendidikan matematika dan pendidikan bahasa inggris, Fakultas Ekonomi dengan 2 Program Studi yaitu manajemen dan akuntansi, Fakultas Ilmu Administrasi dengan 1 program studi yaitu ilmu administrasi negara, Fakultas Peternakan memiliki 1 program studi yaitu pertanian dan Fakultas Teknik memiliki 2 Program studi yaitu informatika dan teknik sipil.
Pada tahun akademik 2016/2017 semester gasal, Universitas Madura telah menerapkan kurikulum berbasis Kerangka Kualifikasi Nasional Indonesia (KKNI) pada Sistem Informasi Manajemen Akademik Terpadu (SIMAT) Universitas Madura, salah satu hal pokok yang ada pada kurikulum KKNI adalah peminatan matakuliah mahasiswa. Setiap program studi memiliki aturan peminatan yang berbeda. Namun pada umumnya, salah satu syarat mahasiswa dapat memilih peminatan jika sudah menempuh beberapa SKS tergantung pada aturan masing masing program studi. Selama ini, mahasiswa meminta saran kepada dosen wali atau ketua program studi untuk memilih peminatan yang cocok untuk dipilih. Ada pula yang memilih peminatan berdasarkan banyaknya peminatan yang di pilih oleh teman mahasiswa lainnya (ikut ikutan). 
Saat ini, Universitas madura memiliki mahasiswa aktif sebanyak 2808 dan telah menjalani kurikulum KKNI selama 2 tahun, selama kurun waktu tersebut muncul permasalahan dan pemikiran mengenai peminatan mahasiswa. Mahasiswa berhak memilih peminatan yang sesuai dengan keinginan mahasiswa meski terkadang tidak sesuai dengan hasil pembelajaran atau nilai matakuliah pendukung peminatan yang pernah mahasiswa tempuh.

Oleh sebab itu perlu adanya penelitian mengenai teknik atau metode yang bisa memberikan rekomendasi kepada pihak tertentu seperti mahasiswa, ketua program studi dan dosen wali agar dapat memberikan rekomendasi pemilihan peminatan yang tepat untuk mahasiswa berdasarkan analisis data dan metode tertentu sehingga mahasiswa tidak merasa menyesal dikemudian hari karena salah memilih peminatan matakuliah yang ada pada kurikulum KKNI sehingga Penelitian ini memiliki urgensi yang sangat penting untuk segera dilakukan mengingat kurikulum KKNI sudah berjalan di Universitas Madura.

\section{TINJAUAN PUSTAKA}

Berikut tinjauan pustaka yang digunakan dalam penelitian ini.

\section{Kerangka Kualifikasi Nasional Indonesia}

Kerangka Kualifikasi Nasional Indonesia disingkat KKNI atau disebut juga sebagai kerangka penjenjangan merupakan patokan dalam pengakuan penjenjangan pendidikan yang dijadikan kerangka acuan. Dalam rangka pemberian pengakuan kompetensi kerja sesuai dengan struktur pekerjaan diberbagai sektor, KKNI dapat diartikan sebagai kualifikasi kompetensi yang dapat mengintegrasikan dan menyandingkan serta menyetarakan antara bidang pendidikan dan pelatihan kerja serta pengalaman kerja [1]. Menurut Perpres No. 08 tahun 2012, "KKNI merupakan perwujudan mutu dan jati diri Bangsa Indonesia terkait dengan sistem pendidikan dan pelatihan nasional yang dimiliki Indonesia". Jadi, dapat disimpulkan bahwa kurikulum berbasis KKNI mengharuskan program studi pada sistem pendidikan di Perguruan Tinggi untuk memperjelas profile alumninya agar dapat disesuaikan dengan kelayakan dan kebutuhan masyarakat.

\section{Sistem Pendukung Keputusan}

Untuk mendukung pengambilan keputusan pada suatu lembaga, perusahaan, atau instansi dapat menggunakan sistem pendukung keputusan (SPK) yang merupakan salah satu bagian dari sistem informasi berbasis pengetahuan[2] atau dapat juga disebut sebagai sistem terkomputerisasi yang menghasilkan informasi dari hasil olah data untuk dijadikan acuan mengambil keputusan dari peristiwa yang spesifik..

SPK dapat digambarkan sebagai sistem yang memiliki kemampuan untuk mendukung pemodelan keputusan, analisis data, orientasi perencanaan masa depan, berorientasi keputusan, serta dapat digunakan pada saat-saat yang tidak biasa.

Untuk menganalisis, mengembangkan, dan menemukan berbagai alternatif tindakan yang mungkin dapat dilakukan merupakan bagian dari kegiatan merancang sistem pendukung keputusan. [3]. Pengembangan dan evaluasi merupakan serangkaian kegiatan alternatif pada tahap perancangan sedangkan kegiatan menelaah dan memilih digunakan untuk memilih satu rangkaian

62 Mohammad tindakan tertentu dari beberapa rangkaian yang tersedia serta melakukan penilaian terhadap tindakan yang telah dipilih.

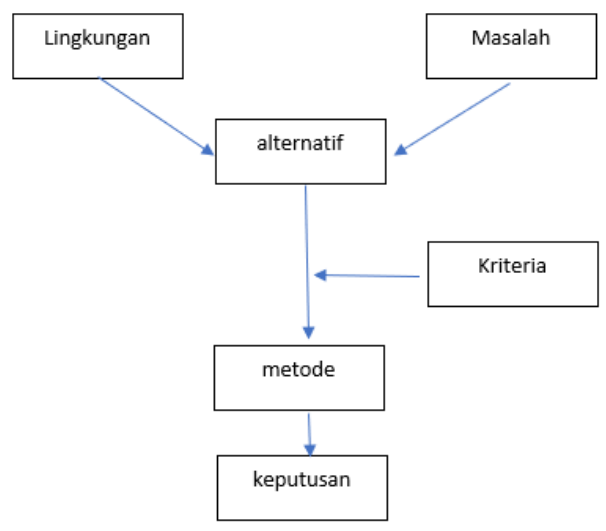

Gambar 1. Diagram Sistem Pendukung Keputusan

\section{Profile Matching}

Metode profile matching merupakan salah satu metode yang dapat digunakan sebagai mekanisme pengambilan keputusan dengan beranggapan bahwa subjek yang diteliti harus memiliki tingkat variabel prediktor yang ideal yang harus dipenuhi [3]. Secara garis besar, proses pencocokan profile merupakan proses membandingkan antara kompetensi individu ke dalam kompetensi profil sehingga diketahui perbedaan nilai skornya atau disebut juga gap[4].

Penghitungan Profile Matching dimulai dengan mengurangi nilai matakuliah pendukung peminatan mahasiswa(MKa) dengan nilai target matakuliah pendukung peminatan $(\mathrm{MKb})$, hasilnya disebut dengan gap.

$\mathrm{Gap}=\mathrm{MKa}-\mathrm{MKb}$

Gap yang telah diperoleh kemudian dikonversi menjadi nilai bobot berdasarkan data bobot yang telah ditentukan, semakin kecil nilai gap maka semakin besar nilai bobotnya. Adapun data nilai gap dan nilai bobot dapat dilihat pada tabel 1 dibawah ini.

Tabel 1. Bobot Nilai

\begin{tabular}{|c|c|c|l|}
\hline No & GAP & $\begin{array}{l}\text { BOBOT } \\
\text { NILAI }\end{array}$ & KETERANGAN \\
\hline 1 & 0 & 7,0 & $\begin{array}{l}\text { tidak ada selisih (kompetensi } \\
\text { sesuai dengan yang } \\
\text { dibutuhkan) }\end{array}$ \\
\hline 2 & 0,5 & 6,5 & $\begin{array}{l}\text { kompetensi individu kelebihan } \\
0,5 \text { tingkat }\end{array}$ \\
\hline 3 & $-0,5$ & 6,0 & $\begin{array}{l}\text { kompetensi individu } \\
\text { kekurangan 0,5 tingkat }\end{array}$ \\
\hline 4 & 1 & 5,5 & $\begin{array}{l}\text { kompetensi individu kelebihan } \\
1 \text { tingkat }\end{array}$ \\
\hline 5 & -1 & 5,0 & $\begin{array}{l}\text { kompetensi individu } \\
\text { kekurangan 1 tingkat }\end{array}$ \\
\hline 6 & 1,5 & 4,5 & $\begin{array}{l}\text { kompetensi individu kelebihan } \\
1,5 \text { tingkat }\end{array}$ \\
\hline 7 & $-1,5$ & 4,0 & $\begin{array}{l}\text { kompetensi individu } \\
\text { kekurangan 1,5 tingkat }\end{array}$ \\
\hline 8 & 2 & 3,5 & $\begin{array}{l}\text { kompetensi individu kelebihan } \\
2 \text { tingkat }\end{array}$ \\
\hline
\end{tabular}

https://doi.org/10.30743/infotekjar.v4i1.1635 


\begin{tabular}{|c|c|c|l|}
\hline No & GAP & $\begin{array}{l}\text { BOBOT } \\
\text { NILAI }\end{array}$ & KETERANGAN \\
\hline 9 & -2 & 3,0 & $\begin{array}{l}\text { kompetensi individu } \\
\text { kekurangan 2 tingkat }\end{array}$ \\
\hline 10 & 3 & 2,5 & $\begin{array}{l}\text { kompetensi individu kelebihan } \\
3 \text { tingkat }\end{array}$ \\
\hline 11 & -3 & 2,0 & $\begin{array}{l}\text { kompetensi individu } \\
\text { kekurangan 3 tingkat }\end{array}$ \\
\hline 12 & 4 & 1,5 & $\begin{array}{l}\text { kompetensi individu kelebihan } \\
4 \text { tingkat }\end{array}$ \\
\hline 13 & -4 & 1,0 & $\begin{array}{l}\text { kompetensi individu } \\
\text { kekurangan 4 tingkat }\end{array}$ \\
\hline
\end{tabular}

Selanjutnya nilai bobot akan dihitung nilai rata-ratanya sesuai dengan type atau jenis kriteria dari variabel tersebut. Terdapat dua type atau jenis variabel yaitu Core Factor dan Secondary Factor. Jumlah komposisi Core Factor dan Secondary Factor harus $100 \%[6]$.

Langkah berikutnya menghitung nilai core factor $(\mathrm{NCF})$ dan secondary factor (NSF). Kriteria penilaian yang paling utama yang harus terkandung dalam sebuah kriteria disebut dengan core factor. adapun perhitungan core factor menggunakan rumus sebagai berikut:

$\mathrm{NCF}=(\in \mathrm{NC}($ kriteria $)) /(\in \mathrm{IC})$

keterangan:

$\mathrm{NCF}=$ Nilai rata-rata core factor

$\in \mathrm{NC}=$ jumlah total nilai core factor

$\in \mathrm{IC}=$ jumlah item core factor

Sedangkan secondary factor (NSF) merupakan kriteriakriteria selain yang ada pada core factor. NSF dihitung menggunakan persamaan (3)

$\mathrm{NSF}=(\in \mathrm{NS}($ kriteria $)) /(\in \mathrm{IS})$

keterangan:

$\mathrm{NSF}=$ Nilai rata-rata secondary factor

$\in \mathrm{NS}=$ jumlah total nilai secondary factor

$\in \mathrm{IS}=$ jumlah item secondary factor

Selanjutnya perhitungan nilai total(NT) masing masing peminatan berdasarkan nilai core factor dan secondary factor menggunakan persamaan 4, Nilai Total Peminatan tertinggi yang direkomendasikan untuk dipilih.

$\mathrm{NT}=(\mathrm{x} \%) * \mathrm{NCF}+(\mathrm{y} \%) * \mathrm{NSF}$

keterangan:

$\mathrm{NT}=$ Nilai Total kriteria peminatan

$\mathrm{x} \%=$ Persentase Core Factor

$\mathrm{NCF}=$ Nilai rata rata core factor

y $\%=$ Persentase Secondary Factor

$\mathrm{NSF}=$ Nilai rata rata secondary factor

Dalam penelitian ini, nilai $\mathrm{x} \%$ yang digunakan adalah $60 \%$ dan nilai y\% yang digunakan adalah $40 \%$.

Selanjutnya memilih nilai total kriteria peminatan terbesar sebagai alternatif terbaik.

\section{Waterfall}

Perangkat lunak yang berkualitas dapat dihasilkan jika pengembangan perangkat lunaknya menggunakan sebuah metode. Metode waterfall dapat dipilih sebagai salah satu metode pengembangan perangkat lunak.

Adapun metode pengembangan perangkat lunak sistem pendukung keputusan menggunakan metode waterfall pada sistem ini dapat dilihat pada gambar 2 dibawah ini.

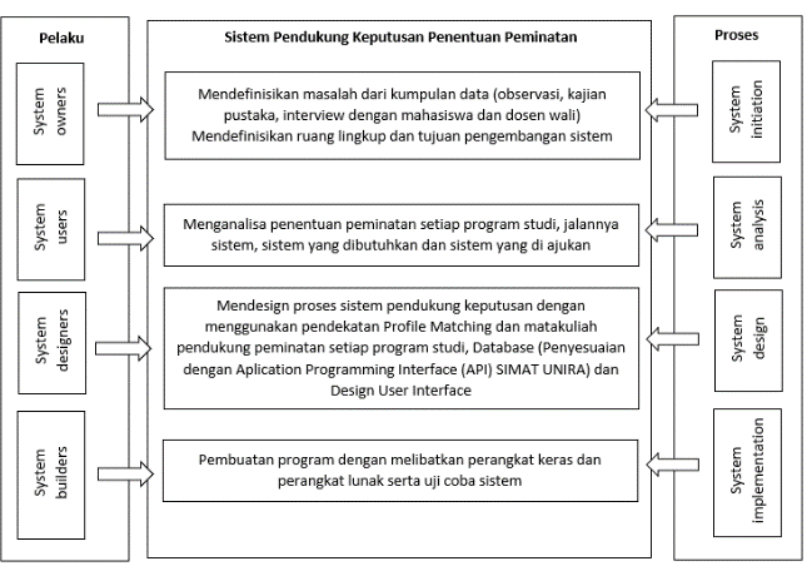

Gambar 2. Model Waterfall Sistem

\section{Peminatan}

Minat merupakan kesadaran seseorang terhadap suatu objek, suatu masalah atau situasi yang berkaitan dengan dirinya. Peminatan merupakan sebuah proses yang di dalamnya melibatkan serangkaian pengambilan pilihan dan keputusan oleh peserta didik atau mahasiswa yang didasarkan pada pemahaman potensi diri dan peluang yang ada di lingkungannya.

\section{METODE PENELITIAN}

Proses untuk memperoleh data yang akan digunakan dalam penelitian ini sebagai berikut.

\section{Pengembangan Perangkat Lunak Sistem}

Berdasarkan pada metode waterfall yang digunakan sebagai metode pengembangan perangkat lunak maka langkah pertama yang dilakukan untuk mendapatkan informasi kebutuhan sistem adalah analisa kebutuhan.

Beberapa analisa kebutuhan yang dilakukan antara lain:

\section{Studi literatur dan lapangan}

Studi literatur yang dilakukan dengan menelaah beberapa jurnal ilmiah serta hasil pencarian di internet pada situs yang kompeten dan dapat dipertanggung jawabkan. Studi lapangan yang dilakukan dengan melakukan wawancara kepada ketua program studi, namun pada contoh perhitungan pada jurnal ini akan menggunakan data dari program studi teknik informatika Universitas Madura. Untuk memperoleh data nilai transkrip dua mahasiswa yang akan dijadikan sample yaitu mahasiswa dengan NIM 2015520001 (M1) dan 2015520002 (M2), serta penentuan matakuliah pendukung dari setiap peminatan yang ada di program 
studi teknik informatika Universitas Madura (Variabel Penghitungan).

\section{Menentukan level pengguna}

level pengguna atau Level user sistem merupakan level hak akses siapa saja yang berhak mengakses sistem. Pada penelitian ini level penggunanya antara lain Admin Sistem, Ka. PRODI dan Dosen Wali.

\section{Software yang dibutuhkan}

Sistem ini dibangun menggunakan teknologi web, sehingga software yang dibutuhkan antara lain browser untuk menjalankan aplikasi, text editor untuk menulis program, PHP sebagai bahasa server side, javascript dan jquery sebagai client sidenya, dan MySQL sebagai databasenya.

\section{Layanan Pendukung}

Data pada aplikasi ini sebagian besar di peroleh dengan mensinkronkan atau mendownload data dari SIMAT UNIRA kemudian disimpan kedalam database sistem. Adapun respon yang diberikan oleh SIMAT UNIRA berupa Aplication Programming Interface (API) yang berbentuk JSON.

\section{Rancangan Sistem}

Rancangan sistem dibuat agar sistem dapat digambarkan dengan baik. Diagram alir sistem dari rancangan sistem yang akan dibuat dapat dilihat pada gambar 3 .

Pada gambar 3, dapat dijelaskan bahwa sistem SPK yang akan dibuat akan melakukan sinkronisasi beberapa data dari database SIMAT UNIRA kedalam database SPK yang akan dibuat melalui konsep web API sehingga tidak perlu terhubung secara langsung dengan database SIMAT. database SPK cukup membuat tabel tabel baru untuk menyesuaikan dengan perhitungan metode profile matching. adapun user dari sistem SPK yang akan dibuat terdiri dari beberapa user antara lain admin, kaprodi dan dosen wali.

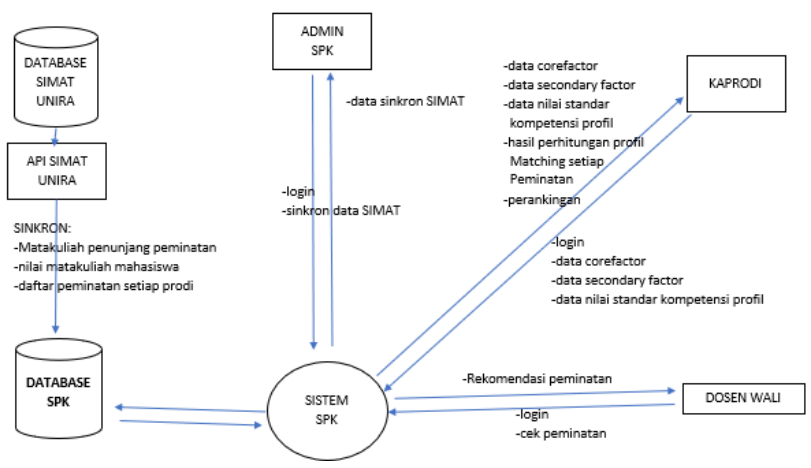

Gambar 3. Diagram Alir Sistem

Adapun alur penentuan peminatan menggunakan metode profile matching dapat dilihat pada gambar dibawah ini.

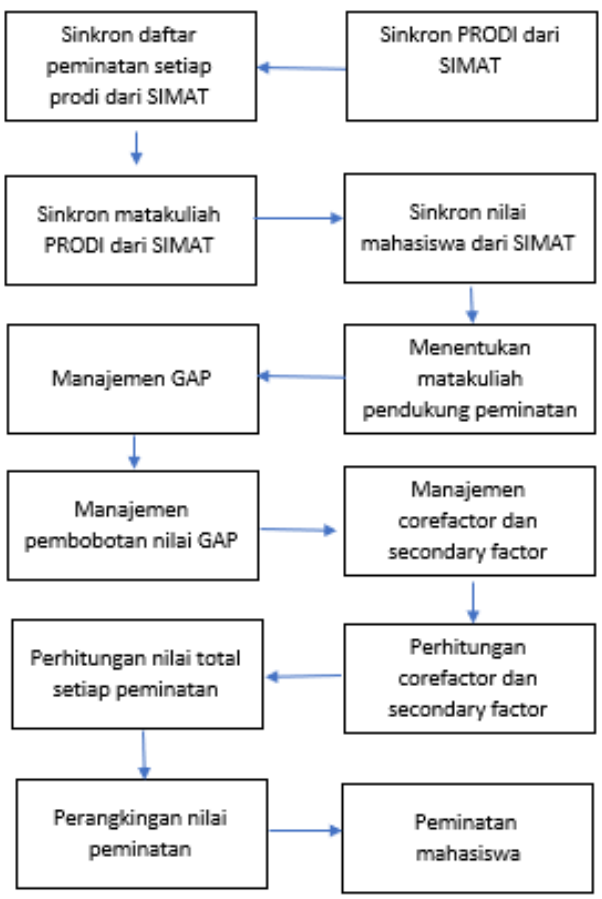

Gambar 4. Alur Profile Matching

\section{Black Box Testing}

Salah satu metode pengujian sistem yang dapat digunakan dalam menguji fungsionalitas aplikasi adalah metode Black Box Testing. Pengujian sistem yang dilakukan adalah dengan mengamati hasil eksekusi sistem melalui data uji kemudian memeriksa kinerja sistem apakah dapat bekerja sesuai dengan alur sistem yang sudah ditentukan[6].

Pengujian lebih difokuskan pada user interface aplikasi sesuai standar dan reaksi apabila terdapat celah dan error pada program aplikasi yang sedang diuji. Tester atau Penguji akan melakukan pengujian terhadap sistem berdasarkan apa yang diamati serta hanya fokus terhadap kinerja dan output sistem.

\section{Skala Likert}

Untuk mengukur pendapat dan sikap responden (mahasiswa), peneliti menggunakan skala likert. Peneliti meminta responden untuk melengkapi kuesioner sebagai bukti pendukung tolak ukur tingkat persetujuan responden terhadap sejumlah pertanyaan. Peneliti telah menetapkan pertanyaan yang digunakan sebagai variabel penelitian.. Adapun format skala likert yang digunakan dapat dilihat pada tabel 2 dibawah ini.

Tabel 2 Skala Likert

\begin{tabular}{|l|l|l|l|l|l|}
\hline Pertanyaan & $\mathbf{1}$ & $\mathbf{2}$ & $\mathbf{3}$ & $\mathbf{4}$ & $\mathbf{5}$ \\
\hline $\begin{array}{l}\text { Apakah anda setuju dengan hasil } \\
\text { rekomendasi peminatan matakuliah } \\
\text { yang diberikan oleh sistem? }\end{array}$ & & & & & \\
\hline
\end{tabular}

Pada tabel 2, kolom angka 1 berarti sangat tidak setuju(STS), kolom angka 2 berarti tidak setuju(TS), kolom angka 3 berarti ragu-ragu(R), kolom angka 4 berarti setuju(S), dan kolom angka 5 berarti sangat setuju(SS). 
Peneliti menggunakan interval skala likert sebesar 20 skala dengan rentang nilai $0 \%-19,99 \%$ berarti Sangat tidak setuju, 20\% - 39,99\% berarti Tidak setuju, 40\% - 59,99\% berarti Raguragu, $60 \%-79,99 \%$ berarti Setuju, $80 \%-100 \%$ berarti Sangat setuju.

\section{HASIL DAN PEMBAHASAN}

Pada bagian ini akan diberikan contoh perhitungan untuk menentukan peminatan matakuliah pada program studi teknik informatika menggunakan analisis metode profile matching beserta .

\section{Matakuliah Pendukung Peminatan}

Detail matakuliah pendukung peminatan dari tiga peminatan yang dimiliki program studi teknik informatika yaitu Sistem Informasi, Sistem Cerdas, dan Jaringan Komputer yang dapat dilihat pada tabel dibawah ini.

Table 3 Pendukung Peminatan Sistem Informasi

\begin{tabular}{|l|l|l|l|}
\hline $\begin{array}{l}\text { Ko } \\
\text { de }\end{array}$ & Mata Kuliah & $\begin{array}{l}\text { Nilai } \\
\text { Target }\end{array}$ & $\begin{array}{l}\text { NCF/N } \\
\text { SF }\end{array}$ \\
\hline A1 & PEMROGRAMAN VISUAL & A & NSF \\
\hline A2 & $\begin{array}{l}\text { INTERAKSI MANUSIA DAN } \\
\text { KOMPUTER }\end{array}$ & A & NSF \\
\hline A3 & $\begin{array}{l}\text { SISTEM INFORMASI } \\
\text { MANAJEMEN }\end{array}$ & A & NCF \\
\hline A4 & $\begin{array}{l}\text { PEMOGRAMAN } \\
\text { BERORIENTASI OBJEK }\end{array}$ & $\mathrm{A}$ & NSF \\
\hline A5 & PEMROGRAMAN WEB & A & NCF \\
\hline A6 & SISTEM BASIS DATA & A & NSF \\
\hline
\end{tabular}

Table 4 Pendukung Peminatan Sistem Cerdas

\begin{tabular}{|l|l|l|l|}
\hline $\begin{array}{l}\text { Kod } \\
\text { e }\end{array}$ & Mata Kuliah & $\begin{array}{l}\text { Nilai } \\
\text { Target }\end{array}$ & $\begin{array}{l}\text { NCF/NS } \\
\text { F }\end{array}$ \\
\hline B1 & KECERDASAN BUATAN & A & NCF \\
\hline B2 & $\begin{array}{l}\text { PENGOLAHAN CITRA } \\
\text { DIGITAL }\end{array}$ & A & NSF \\
\hline B3 & $\begin{array}{l}\text { ALGORITMA \& } \\
\text { PEMOGRAMAN I }\end{array}$ & A & NCF \\
\hline B4 & ALJABAR LINIER \& MATRIK & A & NSF \\
\hline B5 & $\begin{array}{l}\text { ALGORITMA } \\
\text { PEMOGRAMAN II }\end{array}$ & A & NSF \\
\hline B6 & KALKULUS II & A & NSF \\
\hline B7 & LOGIKA MATEMATIKA & A & NSF \\
\hline B8 & ANALISA ALGORITMA & A & NSF \\
\hline
\end{tabular}

Table 5 Pendukung Peminatan Jaringan Komputer

\begin{tabular}{|l|l|l|l|}
\hline $\begin{array}{l}\text { Ko } \\
\text { de }\end{array}$ & Mata Kuliah & $\begin{array}{l}\text { Nilai } \\
\text { Target }\end{array}$ & $\begin{array}{l}\text { NCF/ } \\
\text { NSF }\end{array}$ \\
\hline C1 & $\begin{array}{l}\text { TEKNOLOGI WIRELESS DAN } \\
\text { SISTEM BERGERAK }\end{array}$ & A & NSF \\
\hline C2 & $\begin{array}{l}\text { JARINGAN KOMPUTER } \\
\text { LANJUT }\end{array}$ & A & NSF \\
\hline C3 & $\begin{array}{l}\text { ARSITEKTUR \& ORGANISASI } \\
\text { KOMPUTER II }\end{array}$ & A & NSF \\
\hline C4 & JARINGAN KOMPUTER & A & NCF \\
\hline
\end{tabular}

https://doi.org/10.30743/infotekjar.v4i1.1635

\begin{tabular}{|l|l|l|l|}
\hline $\begin{array}{l}\text { Ko } \\
\text { de }\end{array}$ & Mata Kuliah & $\begin{array}{l}\text { Nilai } \\
\text { Target }\end{array}$ & $\begin{array}{l}\text { NCF/ } \\
\text { NSF }\end{array}$ \\
\hline C5 & $\begin{array}{l}\text { ARSITEKTUR \& ORGANISASI } \\
\text { KOMPUTER I }\end{array}$ & A & NSF \\
\hline C6 & SISTEM OPERASI & A & NCF \\
\hline
\end{tabular}

Adapun data skala nilai dapat dilihat pada tabel dibawah ini.

Tabel 6 Skala Nilai

\begin{tabular}{|r|c|c|}
\hline \multicolumn{1}{|l|}{ No } & Nilai Huruf & Skala Ordinal \\
\hline 1 & $\mathrm{~A}$ & 4,0 \\
\hline 2 & $\mathrm{AB}$ & 3,5 \\
\hline 3 & $\mathrm{~B}$ & 3,0 \\
\hline 4 & $\mathrm{BC}$ & 2,5 \\
\hline 5 & $\mathrm{C}$ & 2,0 \\
\hline 6 & $\mathrm{D}$ & 1,0 \\
\hline 7 & $\mathrm{E}$ & 0,0 \\
\hline
\end{tabular}

\section{Perhitungan Profile Matching}

Contoh perhitungan menggunakan data transkrip dua mahasiswa teknik informatika. Berikut hasil perhitungan berdasarkan pada masing masing peminatan.

Tabel 7 Peminatan Sistem Informasi(SI)

\begin{tabular}{|c|c|c|c|c|c|c|c|c|}
\hline \multirow{2}{*}{ NO } & \multirow{3}{*}{ NIM } & \multicolumn{6}{|c|}{ NILAI MATAKULIAH } & \\
\hline & & \multicolumn{2}{|c|}{ NCF } & \multicolumn{4}{|c|}{ NSF } & \\
\hline KODE & & $\mathbf{A 3}$ & A5 & A1 & A2 & A4 & A6 & \\
\hline 1 & M1 & 3,5 & 4 & 4 & 3 & 4 & 3 & \\
\hline 2 & M2 & 3 & 3 & 3 & 3 & 4 & 3 & \\
\hline \multicolumn{2}{|c|}{ NILAI TARGET } & 4 & 4 & 4 & 4 & 4 & 4 & \\
\hline 1 & M1 & $-0,5$ & 0 & 0 & -1 & 0 & -1 & \multirow{2}{*}{ GAP } \\
\hline 2 & M2 & -1 & -1 & -1 & -1 & 0 & -1 & \\
\hline \multicolumn{8}{|c|}{ KONVERSI GAP KE BOBOT NILAI } & \\
\hline 1 & M1 & 6,0 & 7,0 & 7,0 & 5,0 & 7,0 & 5,0 & \multirow{2}{*}{$\begin{array}{c}\text { BO } \\
\text { BOT }\end{array}$} \\
\hline 2 & M2 & 5,0 & 5,0 & 5,0 & 5,0 & 7,0 & 5,0 & \\
\hline \multicolumn{2}{|c|}{ Nilai Total } & \multicolumn{2}{|c|}{ NCF $(60 \%)$} & \multicolumn{4}{|c|}{ NSF (40\%) } & NT \\
\hline 1 & M1 & \multicolumn{2}{|c|}{6,5} & \multicolumn{4}{|c|}{6,0} & 6,3 \\
\hline 2 & M2 & \multicolumn{2}{|c|}{5,0} & \multicolumn{4}{|c|}{5,5} & 5,20 \\
\hline
\end{tabular}

Dari tabel 7 diperoleh nilai total(NT) untuk peminatan sistem informasi mahasiswa M1 sebesar 6,3 dan M2 sebesar 5,20.

Tabel 8 Peminatan Sistem Cerdas(SC)

\begin{tabular}{|c|c|c|c|c|c|c|c|c|c|}
\hline \multirow{2}{*}{ NO } & \multirow{2}{*}{ NIM } & \multicolumn{8}{|c|}{ NILAI MATAKULIAH } \\
\hline & & \multicolumn{2}{|c|}{ NCF } & \multicolumn{6}{|c|}{ NSF } \\
\hline \multicolumn{2}{|c|}{ KODE } & B1 & B3 & $\begin{array}{l}\text { B } \\
2\end{array}$ & B & $\begin{array}{l}\text { B } \\
5\end{array}$ & $\begin{array}{l}\text { B } \\
6\end{array}$ & $\begin{array}{l}\text { B } \\
7\end{array}$ & $\begin{array}{l}\text { B } \\
8\end{array}$ \\
\hline 1 & M1 & 4 & 4 & 4 & 4 & 4 & 3 & 4 & 3 \\
\hline 2 & M2 & 3,5 & 3 & 3 & 4 & 3 & 3 & 3 & 4 \\
\hline $\begin{array}{l}\text { NILA } \\
\text { TAR }\end{array}$ & & 4 & 4 & 4 & 4 & 4 & 4 & 4 & 4 \\
\hline
\end{tabular}

Mohammad 


\begin{tabular}{|l|l|c|c|c|c|c|c|c|c|c|}
1 & M1 & 0 & 0 & 0 & 0 & 0 & -1 & 0 & -1 & GA \\
\hline 2 & M2 & - & -1 & -1 & 0 & -1 & -1 & -1 & 0 & $P$ \\
\hline
\end{tabular}

KONVERSI GAP KE BOBOT NILAI

\begin{tabular}{|c|c|c|c|c|c|c|c|c|c|c|}
\hline 1 & M1 & 7,0 & $\begin{array}{l}7, \\
0\end{array}$ & $\begin{array}{l}7, \\
0\end{array}$ & $\begin{array}{l}7, \\
0\end{array}$ & $\begin{array}{l}7, \\
0\end{array}$ & $\begin{array}{l}5, \\
0\end{array}$ & $\begin{array}{l}7, \\
0\end{array}$ & 5 , & BO \\
\hline 2 & M2 & 6,0 & $\begin{array}{l}5, \\
0 \\
\end{array}$ & $\begin{array}{l}5, \\
0\end{array}$ & $\begin{array}{l}7, \\
0\end{array}$ & $\begin{array}{l}5, \\
0 \\
\end{array}$ & $\begin{array}{l}5, \\
0 \\
\end{array}$ & $\begin{array}{l}5, \\
0\end{array}$ & $\begin{array}{l}7, \\
0\end{array}$ & $\begin{array}{l}\text { B } \\
\text { OT }\end{array}$ \\
\hline \multicolumn{2}{|c|}{ Nilai Total } & \multicolumn{2}{|c|}{$\begin{array}{l}\text { NCF } \\
(60 \%) \\
\end{array}$} & \multicolumn{6}{|c|}{$\begin{array}{l}\text { NSF } \\
(40 \%)\end{array}$} & NT \\
\hline 1 & M1 & \multicolumn{2}{|c|}{7,0} & \multicolumn{6}{|c|}{6,3} & $\begin{array}{r}6,7 \\
3 \\
\end{array}$ \\
\hline 2 & M2 & \multicolumn{2}{|c|}{5,5} & \multicolumn{6}{|c|}{5,7} & $\begin{array}{r}5,5 \\
7\end{array}$ \\
\hline
\end{tabular}

Dari tabel 8 diperoleh nilai total(NT) untuk peminatan sistem cerdas mahasiswa M1 sebesar 6,73 dan M2 sebesar 5,57.

Tabel 9 Peminatan Jaringan Komputer(JK)

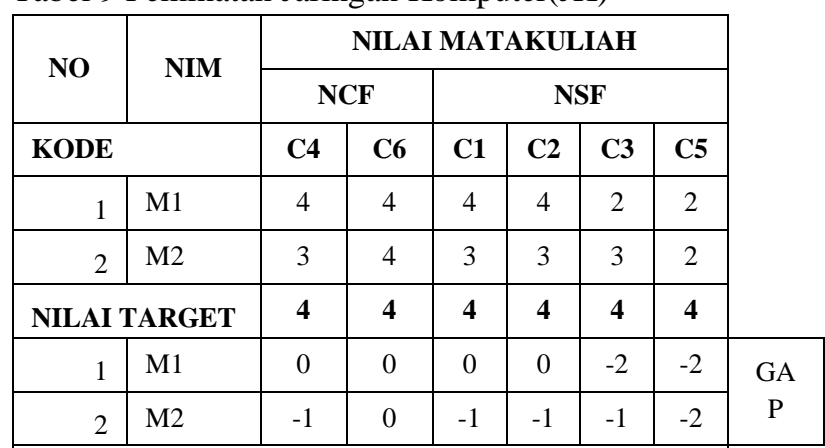

\section{KONVERSI GAP KE BOBOT NILAI}

\begin{tabular}{|c|c|c|c|c|c|c|c|c|}
\hline 1 & M1 & 7,0 & 7,0 & 7,0 & 7,0 & 3,0 & 3,0 & \multirow{2}{*}{$\begin{array}{l}\text { BO } \\
\text { BOT }\end{array}$} \\
\hline 2 & M2 & 5,0 & 7,0 & 5,0 & 5,0 & 5,0 & 3,0 & \\
\hline \multicolumn{2}{|c|}{ Nilai Total } & \multicolumn{2}{|c|}{$\mathrm{NCF}(60 \%)$} & \multicolumn{4}{|c|}{$\begin{array}{c}\text { NSF } \\
(40 \%)\end{array}$} & NT \\
\hline 1 & M1 & \multicolumn{2}{|c|}{7,0} & \multicolumn{4}{|c|}{5,0} & 6,2 \\
\hline 2 & M2 & \multicolumn{2}{|c|}{6,0} & \multicolumn{4}{|c|}{4,5} & 5,40 \\
\hline
\end{tabular}

Dari tabel 9 diperoleh nilai total(NT) untuk peminatan jaringan komputer mahasiswa M1 sebesar 6,2 dan M2 sebesar 5,40. Sehingga, jika hasil nilai total(NT) diperingkat akan menghasilkan data sebagai berikut.

Tabel 10 Rangking Peminatan

\begin{tabular}{|r|l|r|r|c|}
\hline \multicolumn{1}{l|}{ NO } & NIM & \multicolumn{1}{l|}{ SI } & \multicolumn{1}{l|}{ SC } & JK \\
\hline 1 & M1 & 6,3 & $\mathbf{6 , 7 3}$ & 6,2 \\
\hline 2 & M2 & 5,2 & $\mathbf{5 , 5 7}$ & 5,4 \\
\hline
\end{tabular}

Dari tabel 10 dapat dilihat bahwa mahasiswa M1 dan M2 direkomendasikan agar mengambil peminatan Sistem Cerdas (SC) dengan nilai peminatan sistem cerdas untuk M1 sebesar 6,73 dan M2 sebesar 5,57.

\section{Ujicoba Sistem}

Sistem yang dibuat telah diuji coba pada 30 puluh mahasiswa yang berasal dari tiga program studi (masing masing sepuluh mahasiswa) yaitu teknik informatika, pendidikan bahasa dan sastra indonesia, dan pendidikan bahasa inggris dengan hasil sebagai berikut.

\section{Hasil Profile Matching pada Mahasiswa program studi teknik informatika}

Berikut diberikan contoh hasil perhitungan pada mahasiswa program studi teknik informatika dengan NIM yang berbeda.

Tabel 11 Hasil NIM 2016520002

\begin{tabular}{|l|l|l|l|}
\hline PEMINATAN & NCF & NSF & NILAI AKHIR \\
\hline Jaringan Komputer & 5,25 & 7 & 5,95 \\
\hline Sistem Cerdas & 5,5 & 6 & 5,7 \\
\hline Sistem Informasi & 4,8 & 6 & 5,28 \\
\hline
\end{tabular}

Dari table 11 diatas dapat dilihat bahwa mahasiswa dengan NIM 2016520002 lebih baik memilih peminatan Jaringan Komputer dengan nilai hasil perhitungan Profile Matching sebesar 5,95.

Hasil Profile Matching pada Mahasiswa program studi pendidikan bahasa dan sastra indonesia

Berikut diberikan contoh hasil perhitungan pada mahasiswa program studi pendidikan bahasa dan sastra indonesia dengan NIM yang berbeda.

Tabel 12 Hasil NIM 2016610001

\begin{tabular}{|l|l|l|l|}
\hline PEMINATAN & NCF & NSF & NILAI AKHIR \\
\hline $\begin{array}{l}\text { Kajian Bahasa } \\
\text { dan Sastra }\end{array}$ & 4 & 5,167 & 4,47 \\
\hline Jurnalistik & 3,5 & 5,75 & 4,4 \\
\hline
\end{tabular}

Dari table 12 diatas dapat dilihat bahwa mahasiswa dengan NIM 2016610001 lebih baik memilih peminatan Kajian Bahasa dan Sastra dengan nilai hasil perhitungan Profile Matching sebesar 4,47 .

\section{Hasil Profile Matching pada Mahasiswa program studi pendidikan bahasa inggris}

Berikut diberikan contoh hasil perhitungan pada mahasiswa program studi pendidikan bahasa inggris dengan NIM yang berbeda.

Tabel 13 Hasil NIM 2016630003

\begin{tabular}{|l|l|l|l|}
\hline PEMINATAN & NCF & NSF & NILAI AKHIR \\
\hline Journalism & 7 & 7 & 7 \\
\hline Tourism and & 7,5 & 6 & 6,2 \\
\hline $\begin{array}{l}\text { Education } \\
\text { Business }\end{array}$ & 5,1 \\
\hline
\end{tabular}

Dari table 13 diatas dapat dilihat bahwa mahasiswa dengan NIM 2016630003 lebih baik memilih peminatan Journalism dengan nilai hasil perhitungan Profile Matching sebesar 7. 


\section{Gambaran Umum Aplikasi}

Untuk masuk ke dalam sistem, User harus melakukan login terlebih dahulu, sistem akan mengecek level akses user, apakah sebagai admin, ka.prodi atau sebagai dosen wali, berikut tampilan halaman login sistem.

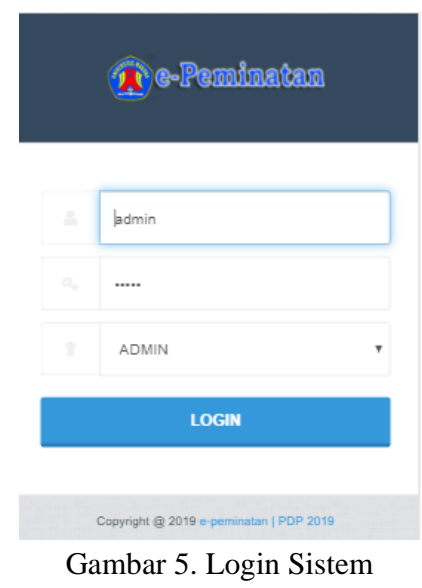

Jika berhasil login, maka akan ditampilkan halaman utama sebagai berikut.

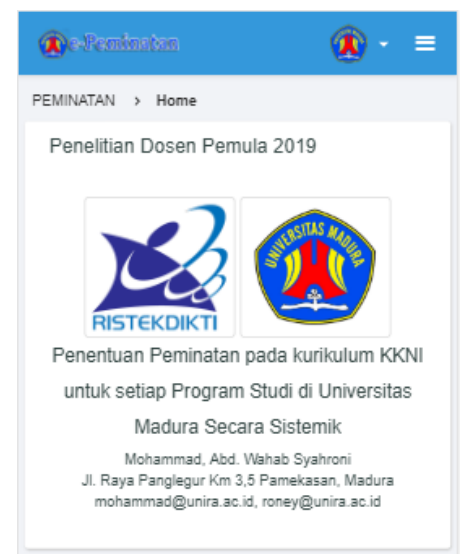

Gambar 6. Halaman Utama

Langkah pertama, user dapat melakukan sinkron data PRODI dari SIMAT UNIRA pada halaman menu PRODI seperti gambar dibawah ini dengan menekon tombol sinkron.

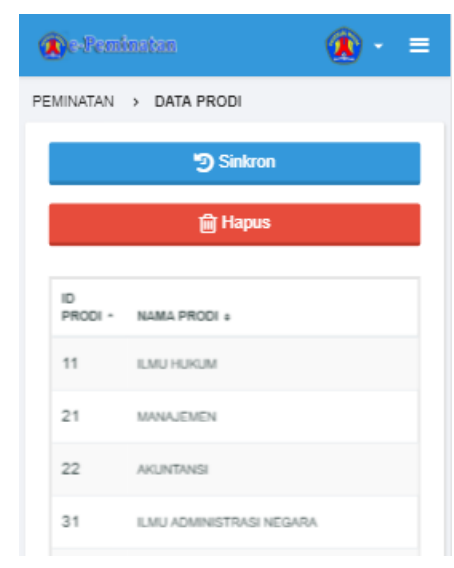

Gambar 7. Halaman PRODI

Jika proses sinkron berhasil maka akan ditampilkan informasi sinkron berhasil, jika sinkron menghasilkan data yang sama dengan sistem maka akan ditampilkan informasi seperti gambar 8 , sedangkan jika sinkron gagal akan ditampilkan informasi atau pesan sinkron gagal seperti gambar 9 .

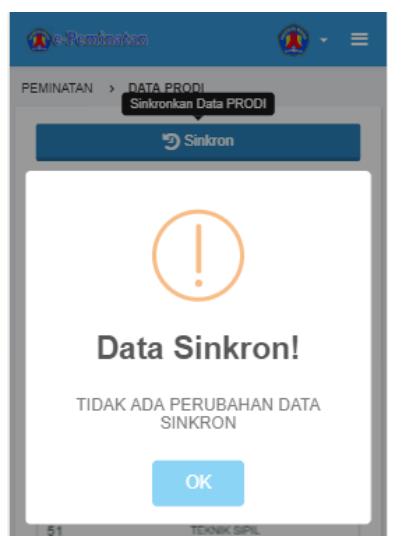

Gambar 8. Data Sinkron Sama

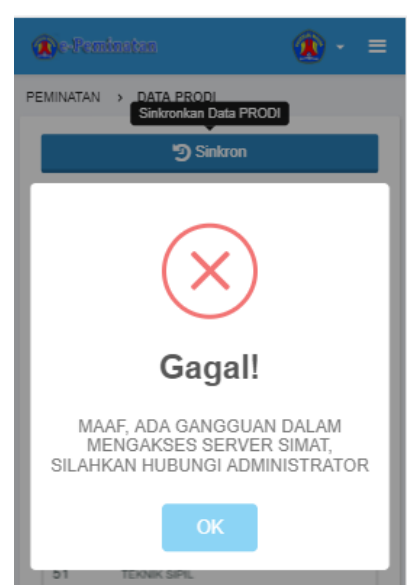

Gambar 9. Sinkron Gagal

Apabila user menekan tombol hapus, sistem tidak akan langsung melakukan penghapusan melainkan memunculkan sebuah pemberitahuan untuk memastikan akan menghapus atau tidak, seperti terlihat pada gambar dibawah ini.

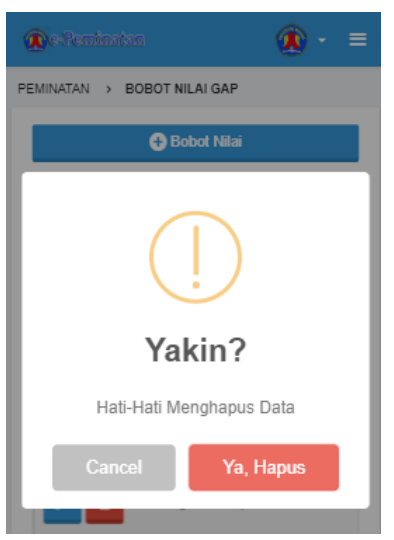

Gambar 10. Pemberitahuan Penghapusan

Halaman manajemen bobot nilai gap dapat dilihat pada gambar 11, halaman matakuliah pendukung dapat dilihat pada gambar 12 dan halaman hasil peminatan dapat dilihat pada gambar 13. 


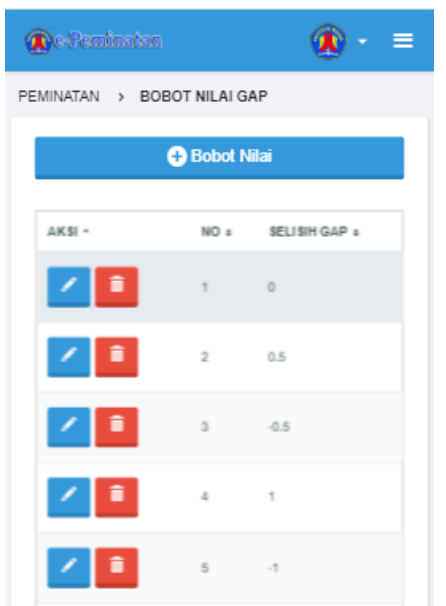

Gambar 11. Manajemen Bobot Nilai GAP

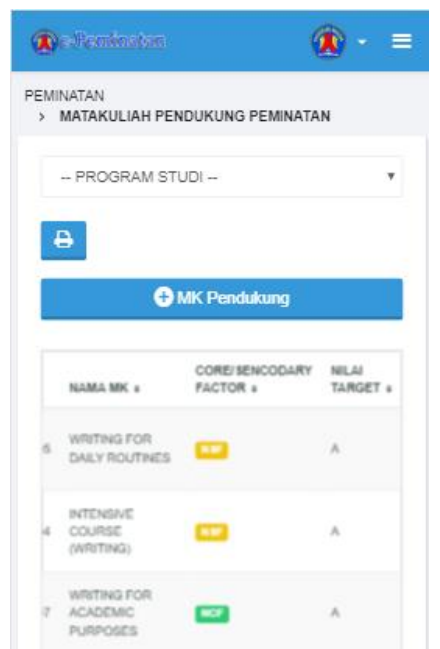

Gambar 12. Matakuliah Pendukung Peminatan

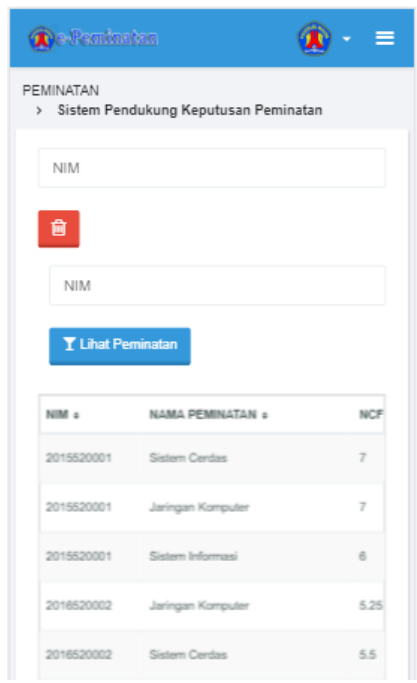

Gambar 13. Hasil Peminatan

\section{Uji Coba Black Box Testing}

Pengujian terhadap aplikasi dilakukan untuk mengetahui kesesuaian antara rancangan awal sistem dengan fungsionalitas sistem yang telah dibuat.

Pengujian dilakukan dengan metode black box dengan cara menguji semua fungsionalitas utama sistem dengan rincian sebagai berikut.
Tabel 14 Black box Test

\begin{tabular}{|l|c|c|}
\hline \multirow{2}{*}{ Fungsionalitas sistem } & \multicolumn{3}{|c|}{ sukses } \\
\cline { 2 - 4 } & Y & T \\
\hline Login & Y & \\
\hline Sinkron dan Hapus PRODI & Y & \\
\hline Sinkron dan Hapus Peminatan PRODI & Y & \\
\hline Sinkron matakuliah PRODI & Y & \\
\hline Tambah matakuliah pendukung peminatan & Y & \\
\hline Sinkron nilai mahasiswa & Y & \\
\hline Manajemen bobot nilai gap & Y & \\
\hline Hasil Profile Matching & Y & \\
\hline
\end{tabular}

Dari tabel 14 diatas, dapat dilihat bahwa semua fungsionalitas sistem yang dibuat telah berjalan dengan baik.

\section{Pengukuran Kelayakan Sistem}

Untuk melihat hasil dan kelayakan sistem yang telah dibuat, sistem ini telah diuji cobakan kepada 30 mahasiswa (responden) dengan pengukuran kelayakan sistem menggunakan skala likert. Dari 30 mahasiswa, 2 mahasiswa menjawab tidak setuju, 20 mahasiswa menjawab setuju dan 8 mahasiswa menjawab sangat setuju.

Indeks kepuasan yang diperoleh dengan menggunakan skala likert dari seluruh jawaban para responden sebesar 82,67\%. sehingga dapat disimpulkan bahwa para responden sangat setuju dengan hasil rekomendasi peminatan yang diberikan oleh sistem.

\section{KESIMPULAN DAN SARAN}

Berikut kesimpulan dan saran dari hasil penelitian ini.

\section{Kesimpulan}

Kesimpulan yang dapat diambil dari hasil ujicoba sistem antara lain.

1. Berdasarkan hasil uji coba, sistem ini memiliki ketergantungan kepada Application Programming Interface (API) SIMAT Universitas Madura karena sebagian besar data diperoleh dengan cara mensinkronkan dengan data SIMAT.

2. Sistem yang dibuat dapat menentukan peminatan matakuliah untuk program studi di Universitas Madura menggunakan metode profile matching.

3. Berdasarkan hasil uji coba sistem menggunakan metode blackbox, semua fungsionalitas sistem dapat berjalan dengan baik.

4. Sistem ini layak untuk digunakan pada setiap program studi di universitas madura berdasarkan indeks kepuasan menggunakan skala likert dari 30 responden dengan nilai $82,67 \%$ yang berarti responden sangat setuju.

\section{Saran}

Berikut saran yang dapat diberikan pada penelitian selanjutnya antara lain.

1. Sistem yang telah dibuat ini dapat langsung disatukan dengan SIMAT UNIRA sehingga tidak bergantung kepada API SIMAT UNIRA.

2. Partisipasi ka.prodi, mahasiswa dan dosen wali dalam menggunakan aplikasi lebih ditingkatkan melalui sosialisasi dan pelatihan. 


\section{Ucapan Terima Kasih}

Kepada Direktorat Riset dan Pengabdian kepada Masyarakat khususnya Direktorat Jenderal Penguatan Riset dan Pengembangan, kami sampaikan terima kasih karen telah memberikan bantuan biaya penelitian kepada peneliti sehingga dapat mengerjakan penelitian ini dengan baik. Serta kepada semua pihak yang terlibat dalam pengerjaan penelitian ini, kami sampaikan terima kasih.

\section{DAFTAR PUSTAKA}

[1] KKNI, 2019. Kerangka Kualifikasi Nasional Indonesia. [Online] Available at: https://id.wikipedia.org/wiki/KKNI [Diakses 12 April 2019].

[2] SYAHRONI, Abd Wahab; RACHMATULLAH, Sholeh. Sistem Pendukung Keputusan Pemilihan Laptop pada Toko Online dengan Metode Fuzzy Tahani. SinkrOn, [S.1.], v. 3, n. 1, p. 143-152, sep. 2018.

[3] Oktopanda. 2017. A Study Approach of Decision Support System with Profile Matching. INTERNATIONAL JOURNAL OF RECENT TRENDS IN ENGINEERING \& RESEARCH. $3.31-44$. 10.23883/IJRTER.2017.3001.ZL93N.

[4] Sulistiyono, M, Bernadhed. 2018. Implementasi Sistem Pendukung Keputusan Seleksi Penerimaan Karyawan Baru dengan Metode Profile Matching. Jurnal Teknologi Informasi (Respati). XIII. 3. 1-9.

[5] Syahroni, Abd Wahab., Ubaidi. 2019. Implementasi Darurat Keamanan Dan Kesehatan Berbasis Mobile Di Desa Waru Barat Pamekasan. Jurnal Nasional Informatika Dan Teknologi Jaringan (INFOTEKJAR) 3. 2. 71-75.

[6] Jaya, Tri Sandhika. 2018. Pengujian Aplikasi dengan Metode Blackbox Testing Boundary Value Analysis. Jurnal Informatika: Jurnal Pengembangan IT (JPIT) 03. 02, 45-48.

[7] Syahroni, Abd Wahab., Ubaidi. 2018. Rancang Bangun Aplikasi Jam Digital Masjid Berbasis Web. Jurnal Teknologi Informasi XIII. 3, 47-55.

[8] Risa Nasriyah, Zainul Arham and Qurrotul Aini, 2016. Profile Matching and Competency Based Human Resources Management Approaches for Employee Placement Decision Support System (Case Study). Asian Journal of Applied Sciences, 9: 75-86.

[9] Sunarti, Rahmadian Y Rangga and Yulvia Nora Marlim. 2017. Application Profile Matching Method for Employees Online Recruitment. IOP Conference Series: Earth and Environmental Science. 1-7.

[10] Faizal, Edi , 2014 . Implementasi Metode Profile matching untuk Penentuan Penerimaan Usulan Penelitian Internal Dosen STMIK El Rahma. Journal Speed. 6. 2088-154.
[11] B.A Herlambang, F.M Dewanto, A.T Harjanta, V.A.V Setyawati. 2018. Implementation of Profile Matching Methods In A Mobile Based Adolescent Nutritional Assesment Systems. TRANSFORMATIKA, Vol.16, No.1, Juli 2018, pp. 1 - 13. ISSN: 1693-3656. 